\title{
PELATIHAN MENULIS BUKU BAGI SANTRI MILLENIAL MELALUI PROGRAM INTELLIGENT WRITTING MOVEMENT
}

\author{
*Agung Mafazi ${ }^{1}$, Fitri Windradi ${ }^{2}$ \\ ${ }^{1,2}$ Program Studi Ilmu Hukum, Fakultas Hukum, Universitas Kadiri
}

*Email: agung_mafazi@unik-kediri.ac.id

\begin{abstract}
Self development activities as an effort to improve one's abilities are activities that need to be continuously activated. In the digital era like now, it is very easy to meet various kinds of works in cyberspace. Some people assume, there are works that are useful and real work that clearly has a value of benefits. Millennial young generation these days are so fond of using technology to search for various information, but sometimes the information obtained does not bring benefits to their achievements and development. One form of enthusiasm is the desire to expose himself in written form, such as making a book or limited to writing articles, but do not have the ability to do so. Training in writing books, especially books on self development for young people, will have an impact on improving their achievements. As for results of this training, participants are expected to have a high level of interest and motivation to make a paper, as well as having the ability to make a script according to standards.
\end{abstract}

Keyword: Writing Book, Development Activities

\begin{abstract}
ABSTRAK
Kegiatan pengembangan diri sebagai upaya untuk meningkatkan kemampuan seseorang merupakan kegiatan yang perlu untuk terus digiatkan. Dalam era serba digital seperti sekarang sangat mudah kita temui berbagai macam karya didunia maya. Sebagian orang menganggap ada karya yang bermanfaat dan ada karya yang kurang baik, sehingga perlu untuk disikapi dengan pengetahuan dan karya nyata yang jelas memiliki nilai manfaat. Generasi muda millenial dewasa ini begitu gemar memanfaatkan teknolgi untuk mencari berbagai informasi, namun terkadang informasi yang didapat kurang membawa manfaat bagi prestasi dan pengembangan dirinya. Salah satu antusiasisme generasi muda millennial saat ini adalah adanya keinginan untuk mengekspose dirinya dalam bentuk karya tulis, seperti membuat buku atau sebatas menulis artikel, tetapi tidak memiliki kemampuan untuk melakukannya. Dengan adannya pelatihan menulis buku ini, khususnya buku tentang pengembangan diri bagi generasi muda akan membawa dampak peningkatan prestasi mereka. Adapun hasil dari pelatihan ini peserta telah memiliki ketertarikan dan motivasi yang tinggi untuk membuat suatu karya tulis, sekaligus memiliki kemampuan untuk membuat naskah yang baik sesuai dengan standart agar lolos penerbit.
\end{abstract}

Kata Kunci : Menulis Buku, Pengembangan Diri

\section{PENDAHULUAN}

Bijak, literate atau "melek" bukan hanya dalam mengelola informasi, melainkan juga mengakses informasi (Ja'far, 2019). Memanfaatkan media informasi menarik (Nurseto, 2012) untuk 
peluang belajar menulis dan berkarya, dari segi akademis kemampuan dalam menulis juga sangat dibutuhkan hingga jenjang pendidikan yang lebih tinggi. Selain itu, sebagai benteng menghadapi tantangan MEA untuk dapat memilah dan menggunakan informasi untuk dijadikan bahan dalam pembangunan bangsa melalui keterampilan yang tercipta dengan penguasaan literasi (Lifia Yola Putri Febrianti dan Oviolanda Irianto, 2017).

Menurut Ibnu Aji Setiawan (2018) peradaban manusia dapat terbangun karena penguasaan literasi yang berbasis pada kegiatan membaca, menulis, dan berpikir kritis dan kreatif. Itulah yang akan menciptakan sebuah gagasan baru untuk kemajuan kualitas bangsa Indonesia menjadi lebih baik lagi (Fitriyanto, 2018). Literasi diperlukan dalam segala lini kehidupan manusia karena kemampuan bisa menjadi kunci manusia untuk berproses menjadi manusia yang lebih berpengetahuan dan berperadaban (Hs, 2009).

Membangun kualitas menulis, dibutuhkan program- program berkelanjutan untuk lebih memperkenalkan buku dan mendorong minat baca buku ke sekolah hingga masyarakat umum. Jangan terpaku pada seremoni, tetapi fokus pada terobosan yang lebih membumi dan memikat kaum muda untuk membaca. Lalu, dari sisi penerbit, kita dorong agar semakin banyak buku diterbitkan, terutama buku-buku yang berkualitas dari berbagai bidang (Permatasari, 2015).

Meningkatkan kemampuan berkarya melalui dunia literasi menjadi penulis buku adalah salah satu program yang sangat penting di terapan pada bidang pendidikan maupun sosial disamping mampu berkarya nyata yang manfaatnya dapat dirasakan diri sendiri, keluarga sekaligus masyarakat luas. Menurut Thomas (2013:56) menyatakan bahwa program literasi berkontribusi dalam meningkatkan prestasi (Sulistyo, 2017) menjadi modal wirausaha, dan menambah finansial. Di samping itu juga dapat membuat produktif (Wulan, 2014) memanfaatkan waktu dengan baik.

Adanya kegiatan pelatihan ini akan meningkatkan kemampuan kognitif, afektif dan kesiapan peserta untuk menyusun kata-kata dalam sebuah kalimat yang mudah dipahami oleh pembaca serta memiliki skill untuk memanajemen ide yang akan dituangkan dalam sebuah naskah.

\section{METODE PELAKSANAAN}

Kegiatan pelatihan menulis buku bagi santri Pondok Pesantren elFawz yang berdomisili di Desa Sitimerto Kecamatan Pagu, Kabupaten Kediri, dengan jumlah peserta yang mengikuti pelatihan sebanyak 40 santri berusia antara 14 sampai 18 tahun yang dilaksanakan pada tanggal 14 Maret 2020. Dalam pelaksanaan kegiatan ini melibatkan 2 ( dua ) dosen, 3 (tiga) mahasiswa Universitas Kadiri dan 2 (dua) guru pendamping dari PPTQ elFawz. Dimana salah satu mahasiswa yang terlibat adalah mahasiswa yang telah berhasil menulis beberapa buku dan telah diterbitkan. Metode pelatihan, sebelum memberikan pelatihan menulis buku terlebih dahulu diadakan kegiatan bedah buku karya mahasiswa Universitas Kadiri yang berjudul "Ledakan Semangat Pemenang" dengan tujuan untuk menimbulkan ketertarikan dan motivasi peserta dalam menulis buku. Kegiatan bedah buku ini dilakukan secara sepintas saja sebagai pembuka membangun nuansa pelatihan yang menyenangkan. Setelah peserta nampak adanya ketertarikan 
dan timbul motivasi, kegiatan dilanjutkan dengan memberikan pelatihan inti menulis buku. Penyampaian materi dilakukan secara verbal dengan cara mempresentasikan melalui media proyektor dan papan tulis, serta didukung dengan buku panduan yang dibagikan kepada seluruh peserta, setelah mendengarkan seluruh materi, diadakan sesi tanya-jawab untuk mengetahui sejauhmana pemahaman para peserta dalam menyerap materi yang disampaikan. Selanjutnya setiap peserta diminta untuk membuat suatu judul naskah dan mempresentasikan muatan serta maksud dari judul naskah yang mereka buat. Untuk mempermudah teknis presentasi terlabih dahulu dibuat suatu kerangka dari hasil kesepakatan bersama tentang tema dan topik naskah, yang pada akhirnya dipilih 10 judul terbaik yang telah memenuhi syarat dalam membuat judul naskah.

\section{HASIL DAN PEMBAHASAN}

Mengamati hasil dari pelatihan ini setidaknya adalah 5 (lima) manfaat yang dapat diambil oleh peserta, Pertama, Peserta timbul motivasi untuk menulis buku tentang pengembangan diri, Kedua, Peserta memiliki wawasan akan cara pandang seorang penulis buku. Ketiga, Peserta memiliki ilmu dan pengetahuan tentang cara menulis buku pengembangan diri beserta tip-tip agar lolos penerbit. Keempat, Peserta mampu mengekspresikan ide dan perasaannya dalam sebuah tulisan yang bermanfaat dan Kelima, Peserta memiliki kemampuan verbal untuk mempresentasikan hasil dari apa yang ditulisnya. Berikut 10 judul terbaik hasil dari pelatihan ini yaitu : 1. "AlQur'an alasan Hijrahku” oleh Mita Srinurdin, 2. "Do'a di Sujud Terakhirku" oleh Syarifah Hanifah, 3. "Goresan Sejarah" oleh Fathiya Adila, 4. “True Happiness" oleh Reza Pahlevi, 5. "Api Semangat” oleh Basilia Adun Azaria, 6. "Selalu Ada Rintangan" oleh Salma Kholiza, 7. "Maju Peradaban bersama AlQur'an” oleh Fernanda Salsabila Putri Muntolalo, 8. "Kemauan bukan Keinginan" oleh Ervina Yuniarti, 9. "Meraih Kesuksesan bersama Al Quran" oleh Khalifah, 10. "Jubah dan Mahkota Kemuliaan untuk Orangtua" oleh Muhammad Muttakim Hidayatulloh

Untuk pengembangan dari hasil pelatihan ini seluruh peserta diminta membuat naskah secara utuh dengan tema "Dunia Santri Penghafal Surah Ilahi”, dengan ketentuan tiap peserta menulis sebanyak 4-5 halaman, yang kemudian akan dirangkum dan dijadikan sebuah buku antalogi karya santri, dengan target selesai dalam waktu 2 minggu. Dalam proses penulisan naskah diadakan diskusi online melalui group whatsapp (WA), setiap santri dapat langsung berinteraksi secara online melalui group tersebut, sekaligus untuk memantau perkembangan dan mengetahui kendala-kendala yang dialami.

Sebagai bahan evaluasi penulis menyadari akan kondisi bangsa saat ini yang sedang terkena wabah Covid-19, dimana beberapa hari setelah pelaksanaan kegiatan ini para santri diliburkan dan dipulangkan ke daerah masing-masing, sebagai bentuk kebijakan dari pimpinan PPTQ elFawz untuk melindungi dan menjaga para santri dari penyebaran wabah Covid-19. Hal ini menjadi kendala tersendiri karena harus merubah program pemantauan pengembangan kegiatan yang harusnya dilakukan 1 minggu 
setelah kegiatan dilaksanakan dengan datang langsung ke lokasi untuk membahas naskah santri yang telah selesai, menjadi tidak dapat dilakukan dan hanya bisa dilakukan secara daring. Para santri diketahui ternyata tidak semuanya memiliki smartphone, sehingga menjadi kendala untuk proses pemantauan penulisan naskah. Pada akhirnya berdasarkan hasil evaluasi bersama dengan guru santri disepakati untuk menunda pelaksanaan kegiatan pengembangan dan memperpanjang waktu penulisan naskah sampai kondisi normal kembali.

Berikut adalah dokumentasi kegiatan Pelatihan menulis Buku di PPTQ elFawz Kediri :

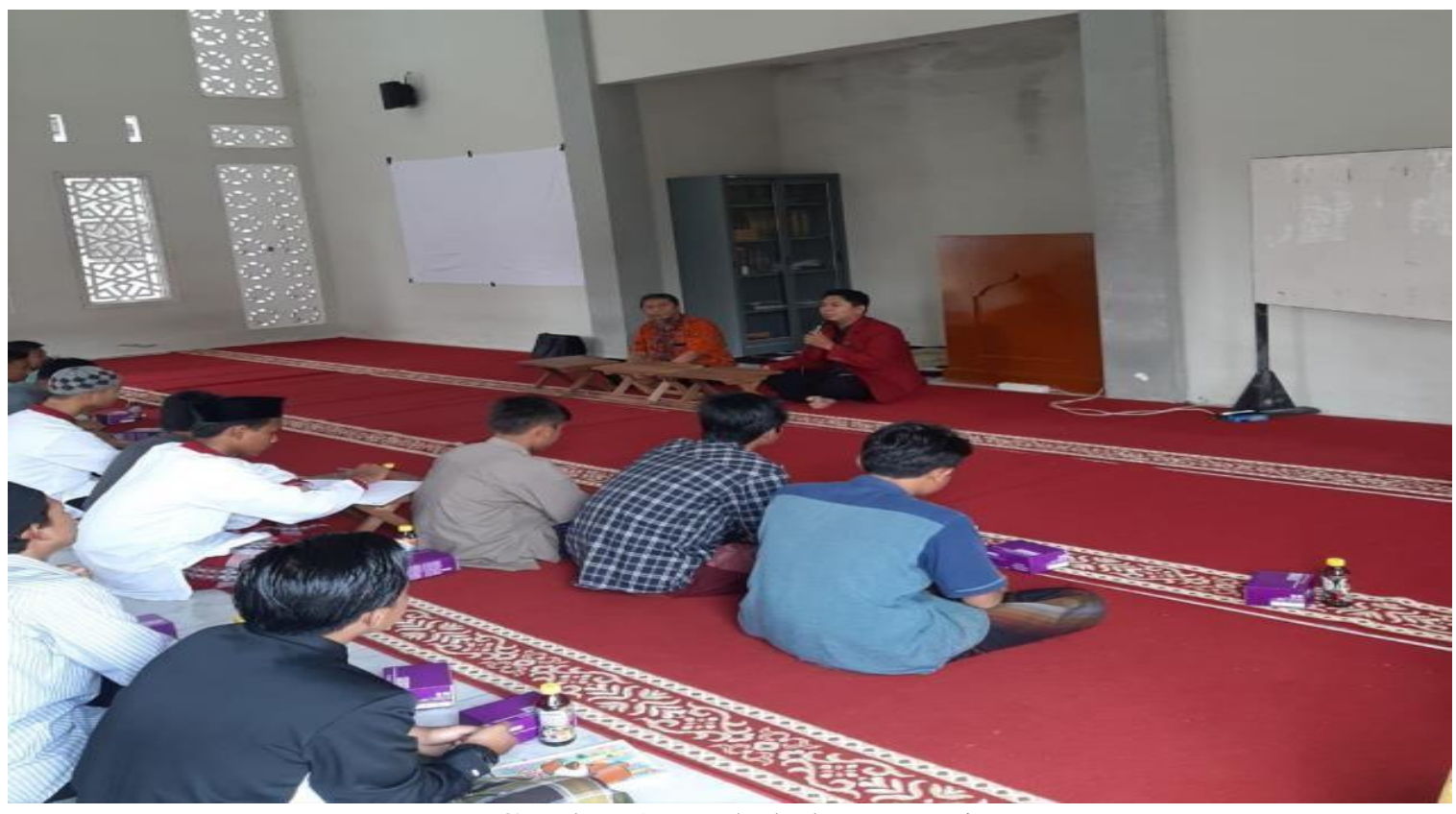

Gambar.1 Pembekalan Materi

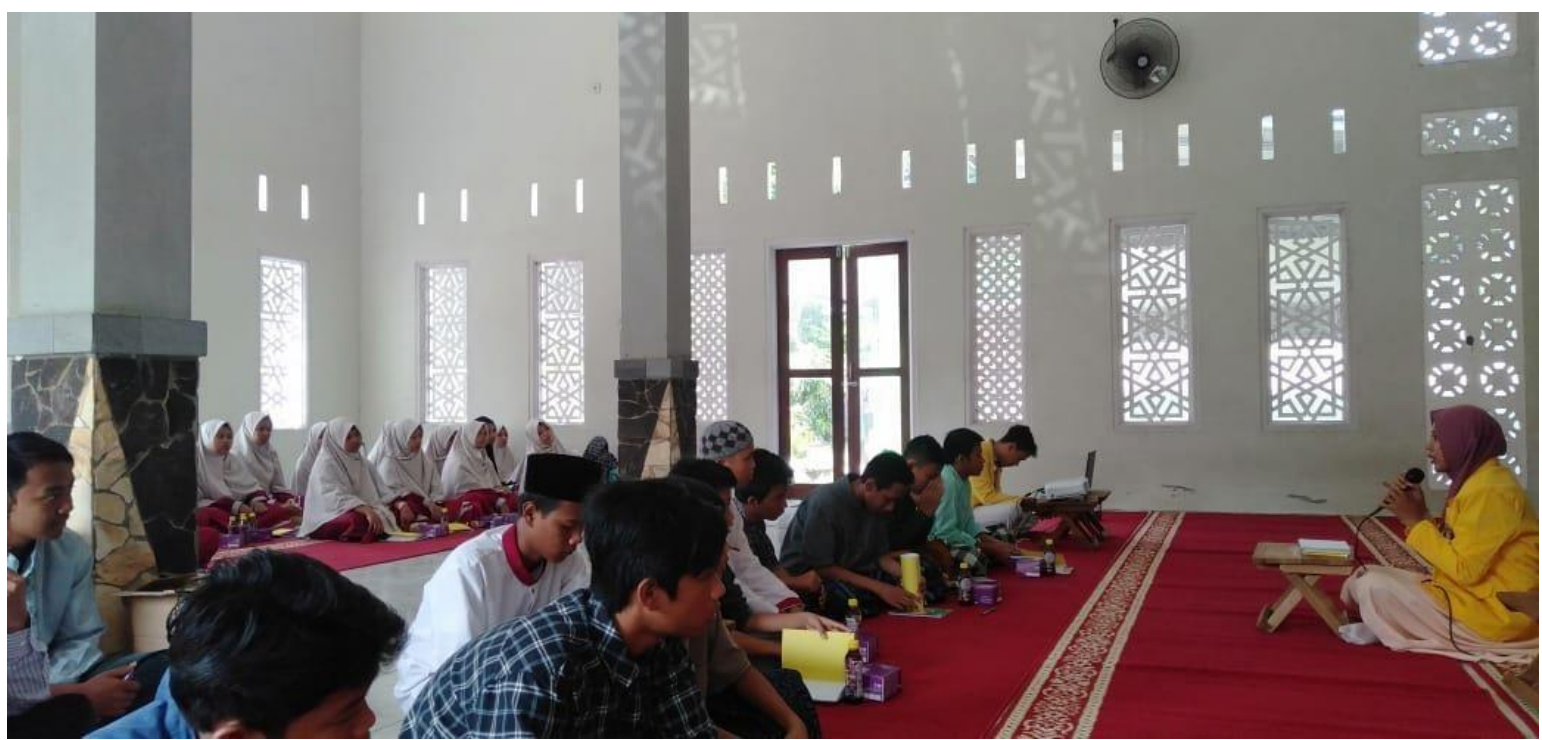

Gambar.2 Bedah Buku "Ledakan Semangat Pemenang” karya Mahasiswa Universitas Kadiri 


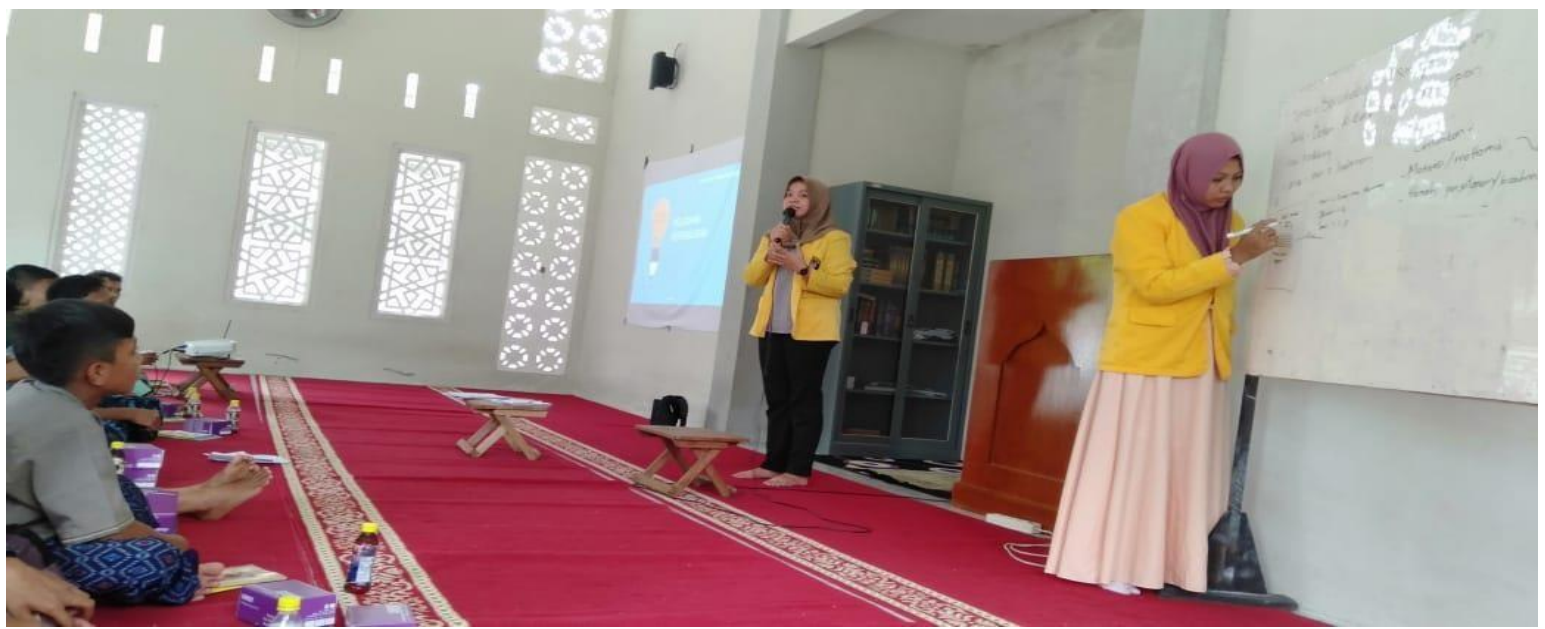

Gambar.3 Penyampaian Materi “Teknis menulis Buku”

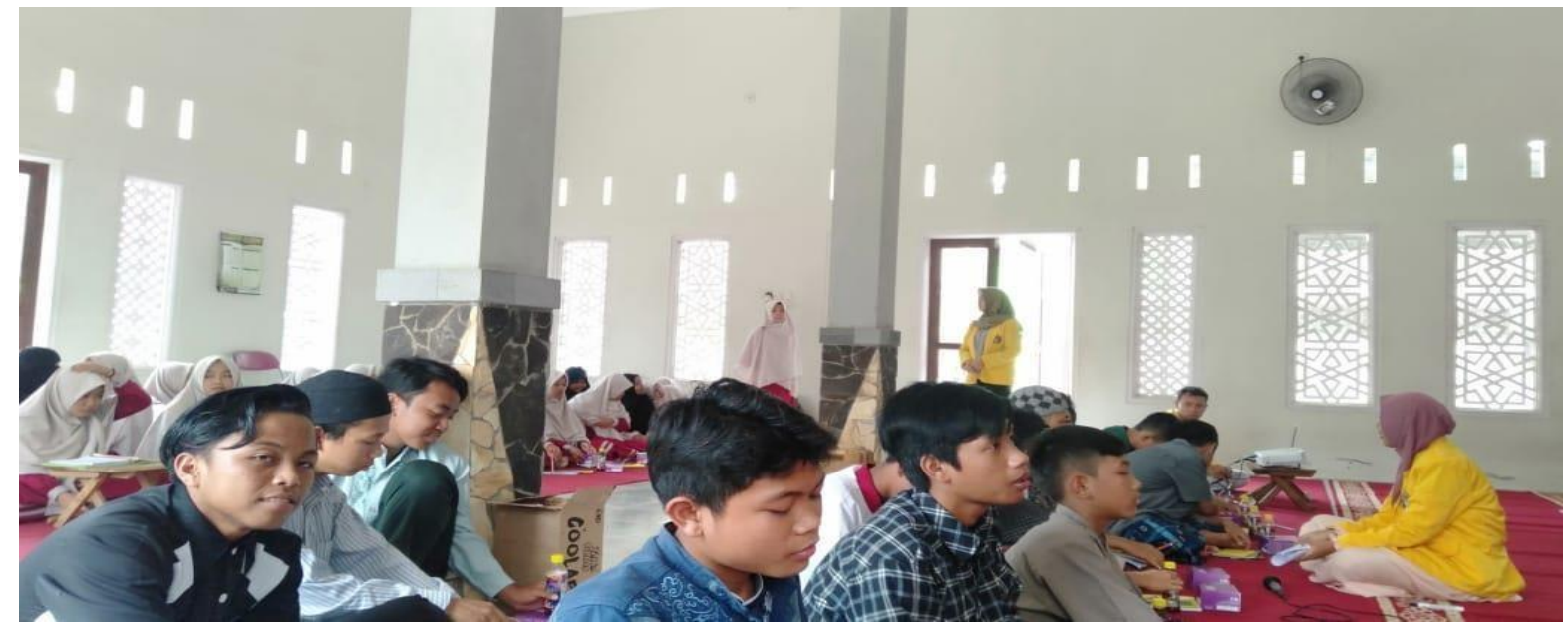

Gambar.4 Diskusi Interaktif Ide-Ide tulisan buku

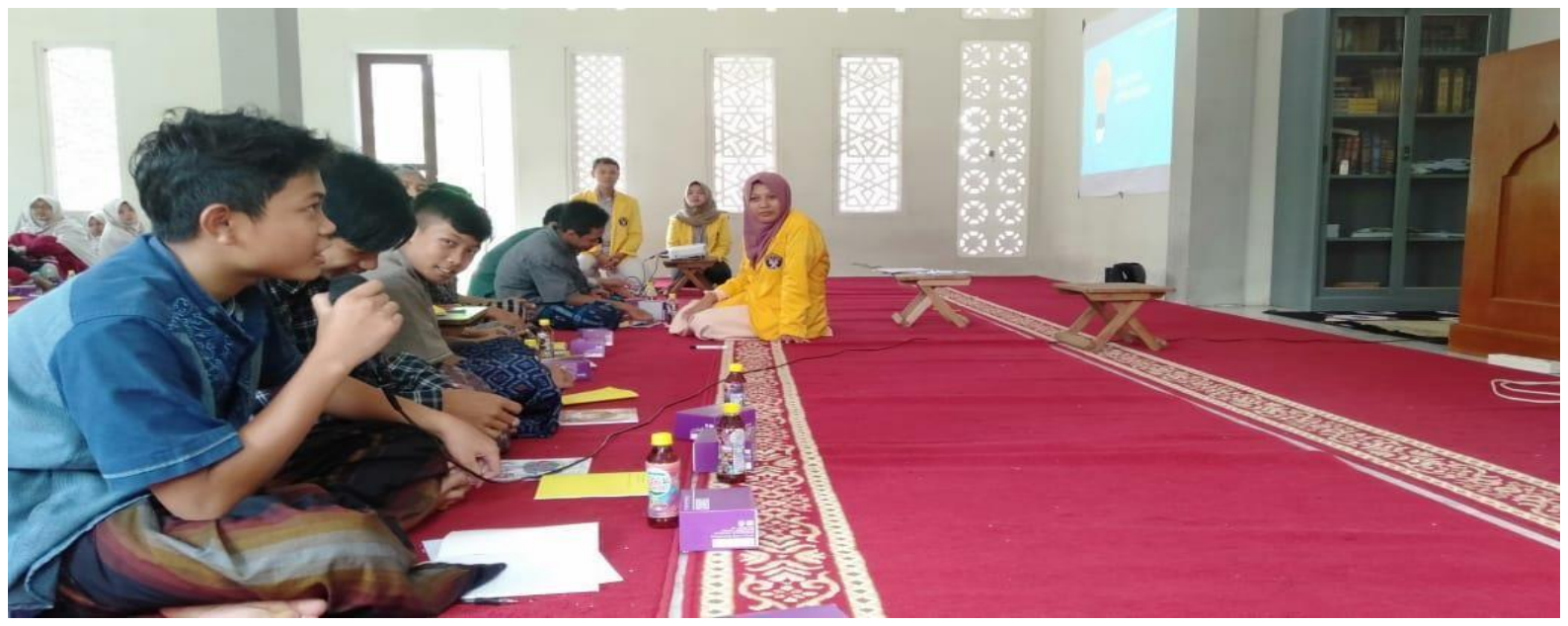

Gambar.5 Tanya-Jawab tentang Pembuatan Naskah 


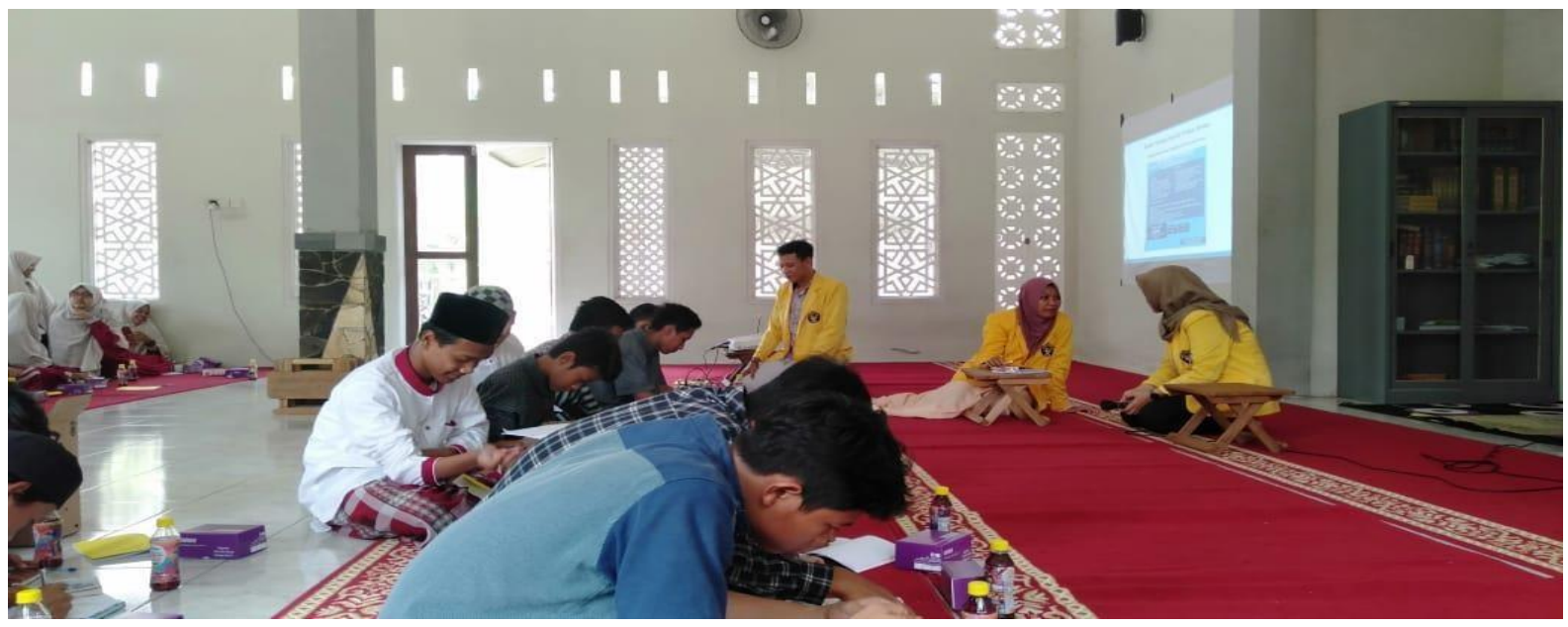

Gambar.6 Pendampingan Pembuatan Judul dan Kerangka Naskah

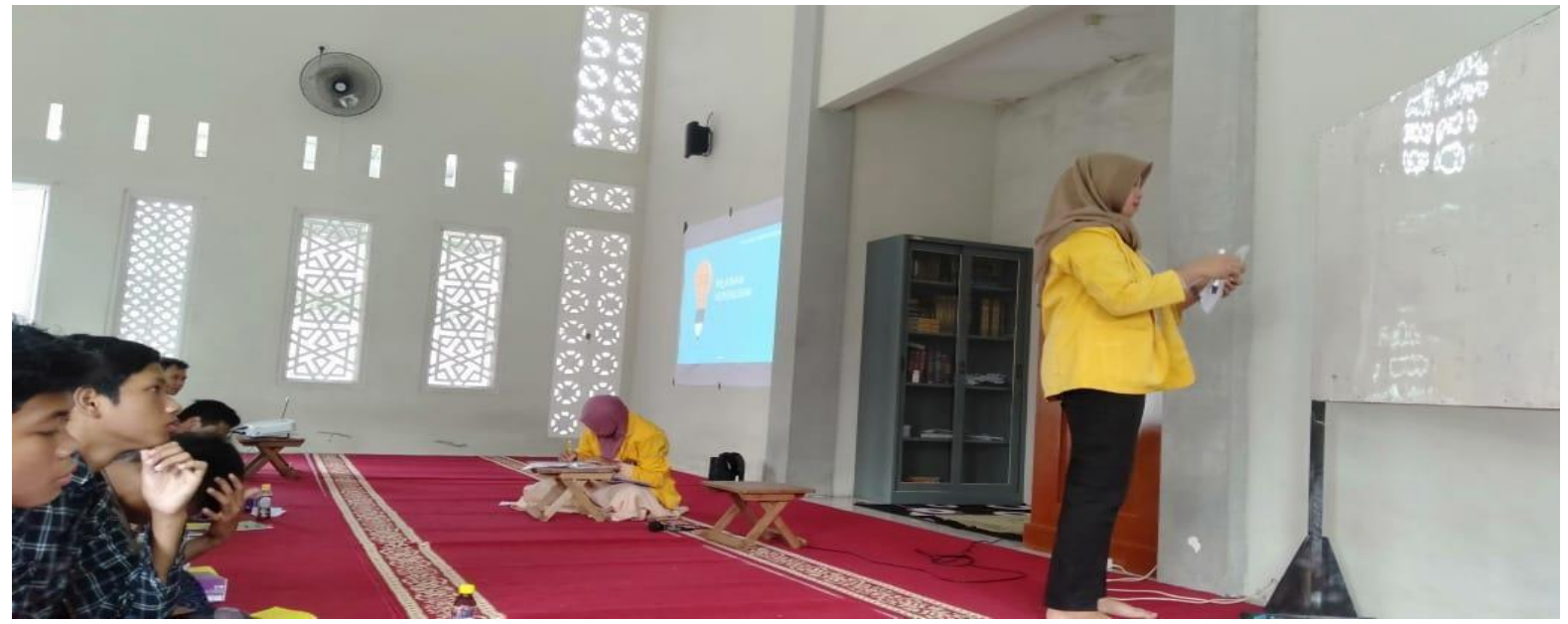

Gambar.7 Pemilihan Judul dan Kerangka Naskah Terbaik
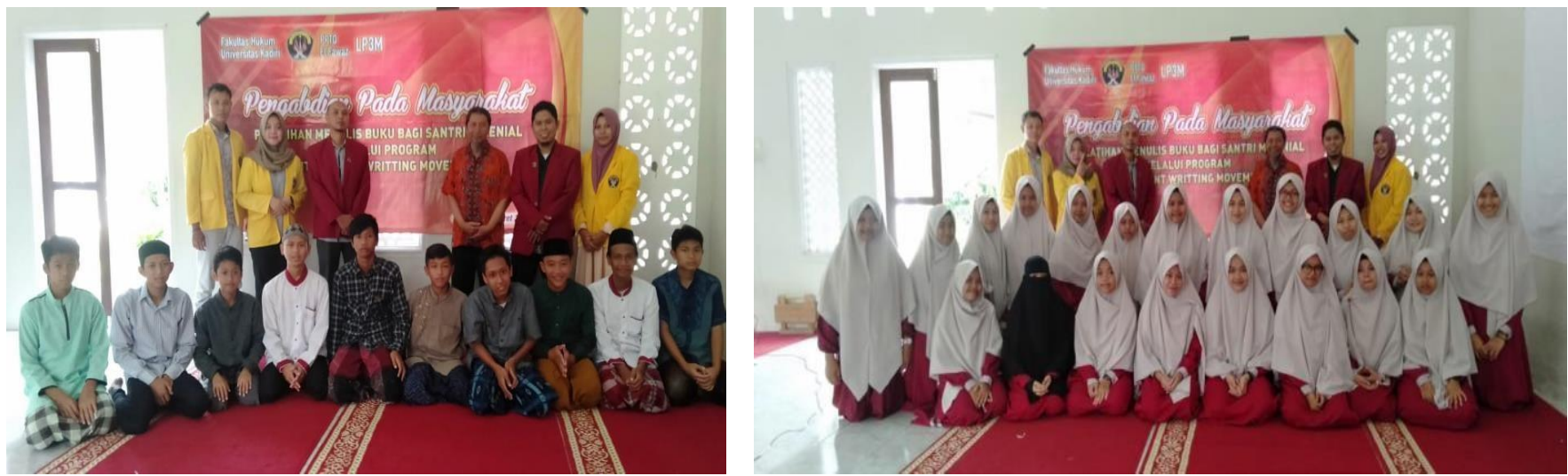

Gambar.8 Foto Bersama santri dan santriwati PPTQ elFawz Kediri

Antusias para santri ketika mengikuti pelatihan tampak pada sesi tanya-jawab dan sesi presentasi judul dari naskah yang akan dibuat. Para santri seakan berlomba untuk mempresentasikan naskah yang akan dibuatnya dengan menceritakan pengalaman-pengalaman indah, haru dan hal-hal "lucu" yang terjadi 
setelah menjadi seorang santri penghafal Al Qur'an. Dengan telah terlaksananya kegiatan pelatihan menulis buku melalui program "Intelligent Writing Movements" diharapkan para santri dapat menjadi seorang penulis buku khususnya buku tentang pengembangan diri sekaligus sebagai penggerak bagi generasi millennial agar gemar untuk menulis buku.

\section{DAFTAR PUSTAKA}

Fitriyanto, D. 2018. Peran Netizen Dalam Membentuk Opini Publik (Studi Kasus Pada Siswa SMKN 4 Bekasi). Jurnal Abdimas BSI. 1(3):526-532.

Hs, L. 2009. Peran Perpustakaan Dan Penulis Dalam Peningkatan Minat Baca Masyarakat. Visi Pustaka. 11(2):6-14.

Ja'far, A. 2019. Literasi Digital Pesantren: Perubahan Dan Kontestasi. Islamic Review: Jurnal Riset Dan Kajian Keislaman. 8(1):17-35.

Lifia Yola Putri Febrianti dan Oviolanda Irianto. 2017. Pentingnya Penguasaan Literasi bagi Generasi Muda dalam Menghadapi Mea. 640-647.

Nurseto, T. 2012. Membuat Media Pembelajaran yang Menarik. Jurnal Ekonomi Dan Pendidikan. 8(1):19-35.

Permatasari, A. 2015. Membangun Kualitas Bangsa dengan Budaya Literasi.

Seminar Nasional Bulan Bahasa UNIB. 146-156.

Solikhatun, Y. U. 2013. Educational Psychology Journal. Educational Psychology Journal. 2(1):65-72.

Sulistyo, A. 2017. Evaluasi Program Budaya Membaca Di Sekolah Dasar Negeri. Kelola: Jurnal Manajemen Pendidikan. 4(1):48.

Suragangga, I. M. N. 2017. Mendidik Lewat Literasi Untuk Pendidikan Berkualitas. Jurnal Penjaminan Mutu. 3(2):154-163.

Wulan, S. 2014. Produktivitas dan Tingkat Kolaborasi Penulis dalam Karya Tulis Ilmiah Peneliti Bidang Zoologi, Puslit Biologi-Lipi 2005-2010. Visi Pustaka. 16(2):176-18 